\title{
Pepakura e Educação Patrimonial: Construção de Modelos de Edificações Históricas da Cidade de Salvador
}

Pepakura and Heritage Education: Salvador City Historical Buildings Model Construction

\author{
> Lucas Figueiredo Baisch \\ NEPAUR-UNIFACS e GREMM-UFBA, Brasil \\ lucas.baisch@gmail.com
}

\author{
$>$ Luis Gustavo Gonçalves Costa \\ UNIFACS, UNIME, Brasil \\ costaluisg@gmail.com
}

\begin{abstract}
The Heritage Education is a way of approaching the historical architecture of their communities of students. Through playfulness, it is possible to explore new forms of human cognition to arouse interest and curiosity in their own history and identity. In this research, it is proposed that the planning of the São Francisco de Assis Church in Salvador, Bahia, Brazil, for the assembly of your model for primary school students. For this, SketchUp ${ }^{\circledast}$ software for modeling, Pepakura Designer ${ }^{\circledR}$ for planning and AutoCAD ${ }^{\circledR}$ for finalization and printing are used.
\end{abstract}

Keywords: Objetos de aprendizagem, Educaçâo Patrimonial, Papekura, Patrimônio Histórico.

\section{Introdução}

A pesquisa situa-se na relação de solidariedade entre os grupos de pesquisa do Núcleo de Ensino, Extensão e Pesquisa em Arquitetura e Urbanismo (NEPAUR) da Universidade Salvador (UNIFACS) e o Grupo de Estudos em Museologia, Museus e Monumentos (GREMM) da Universidade da Bahia (UFBA). Ambos os grupos possuem como objeto de estudo, a cidade de Salvador e usem-se com o intuito de desenvolver objetos de aprendizagem.

Dentre os estudos em conjunto, estão os projetos de pesquisa "Modelos tridimensionais planificados de edificaçóes históricas de Salvador como instrumento de educação patrimonial (1763 - 1889)", aprovado no edital de Pesquisa da UNIFACS 2014-2015 e o projeto de pesquisa "Cidade capital/cidade patrimônio: História, Memória e Inovação na cidade de Salvador-Bahia /1549-2014 - Primeira Etapa: 1549 a 1763", aprovado junto ao Conselho Nacional de Desenvolvimento Científico e Tecnológico (CNQp) (Costa, 2013).

Portanto, esta pesquisa busca contribuir com o conhecimento da história e patrimônio da cidade de Salvador-BA através da construção de modelos físicos tridimensionais produzidos com softwares de modelagem e planificação. Procura-se colaborar com a gestão cultural, no intuito de produzir objetos de aprendizagem, propor açôes educativas em escolas de ensino fundamental e estimular a responsabilidade cidadã na salvaguarda desse patrimônio. Desse modo, estimula-se os estudantes a investigarem novos conhecimentos, para conhecer melhor e entender a realidade que os cerca, ter noçóes de pertencimento, identidade e, assim, preservarem o seu patrimônio cultural.
Uma possível ação para isso é a educação patrimonial, uma vez que as cidades são produtos de ações humanas e suas memórias e lugares constituem seu patrimônio, ou seja, são formas concretas impregnadas de história (Costa, 2013). A arquitetura, com seus elementos construtivos, museus, monumentos e edificações, é parte integrante da cidade e, nesse sentido, conhecê-la é indispensável para compreensão da história e da preservação dessa memória.

\section{Objetos de aprendizagem na educação patrimonial}

Os recursos pedagógicos para facilitar o acesso e assimilação de conhecimento, auxiliados por um objeto de aprendizagem, evocam a Educação Patrimonial, compreendida como o desenvolvimento de uma visão crítica sobre o patrimônio cultural e sua leitura para a busca e entendimento sobre saber.

Segundo Horta (1999), a educação patrimonial baseia-se em princípios e metodologia que visam a sensibilizar e instrumentalizar os individuos de uma comunidade, no universo escolar e fora dele, crianças e adultos, para o reconhecimento, a compreensão e a valorizaçāo do seu patrimônio cultural. Nesse sentido a educação patrimonial objetiva a capacitação de uma comunidade para a descoberta e identificação de seus valores, de sua identidade cultural, de seu modo de fazer e de viver, de pensar e de agir, a partir de suas experiências e do seu cotidiano. Ao apropriar-se do sentido e da peculiaridade de suas manifestaçóes, em todos os aspectos da vida diária, estes individuos tendem a modificar sua atitude, em relação aos seus bens, tangiveis e intangiveis, a recuperar os sentimentos de auto-estima, auto-afirmaçao e cidadania (p. 13). 
Propóe-se, então, que essa apropriação seja uma ação lúdica, uma vez que, a ludicidade auxilia o processo de aprendizagem. Além disso, educadores acreditam que a brincadeira, ou toda situação que permita descontração e imaginação, é fundamental para o desenvolvimento social e intelectual (Vigotsky, 1989). O lúdico permite uma maior interação física e social, desperta interesse e curiosidade, instiga a açóes de pensamentos próprios, ao compartilhamento e ao respeito a regras e opinióes. Segundo Wajskop (1995, p. 25), a criança desenvolve-se pela experiência social, nas interaçóes que estabelece, desde cedo, com a experiência sócio-histórica dos adultos e do mundo por eles criado. Dessa forma, a brincadeira é uma atividade humana na qual as crianças são introduzidas constituindo-se em um modo de assimilar e recriar a experiência sócio-cultural dos adultos.

Para esta pesquisa, o objeto de aprendizagem escolhido são modelos tridimensionais físicos para montagem, uma vez que ele assume um valor de meio de comunicação da ideia arquitetônica, quando separado de sua função de representação, segundo Basso (2005, p.48) como um objeto de registro histórico, que revela hoje a forma de criação e a concepçáo de alguma arquitetura do passado.

\section{Aspectos Metodológicos}

O projeto tem como produto, a publicação de fascículos impressos da história de Salvador dividida em três momentos: Capital da Colônia, Cidade enquanto Brasil Império e Salvador enquanto Brasil República (Costa, 2013). Neste artigo, trata-se apenas da primeira etapa e é selecionado para estudo a Igreja de Sáo Francisco (1585). Para cada fascículo, publicaçáo editada em cadernos e ordem numérica cronológica, conta com a história da edificação, seus elementos arquitetônicos, personagens históricos relacionados a ela e a planificação para a montagem em três dimensóes.

O primeiro fascículo publicado traz uma base topográfica simplificada do Centro Antigo do período da Cidade Capital para a inserção dos modelos. Os posteriores contém as edificações, uma por publicação. Ao montar o último fascículo, o aluno completa a coleção desse período da história de Salvador em uma ação de educação patrimonial.

A pesquisa está dividida em três etapas distintas. Inicia-se com a revisão de literatura em busca do estado da arte da educação patrimonial e dos objetos de aprendizagem ligados ao patrimônio arquitetônico no Brasil, através de artigos apresentados em congressos acadêmicos. Nessa etapa, estuda-se a história do Centro Antigo de Salvador e da edificação, a Igreja de São Francisco de Assis. A segunda etapa, no estudo sobre os softwares utilizados para modelagem digital e planificação atraves de testes, simplicação da geometria, compatibilidade de informaçóes entre eles e a preparação do material para a impressão. A terceira e última etapa é impressão, na qual se testam os diferentes tipos papéis, a montagem do modelo, a otimização de papel, reprodução das cores, escala de texturas e a facilidade de manuseio.

A edificação

O conjunto urbanístico e arquitetônico contido na poligonal do Centro Histórico da cidade de Salvador - declarado Patrimônio

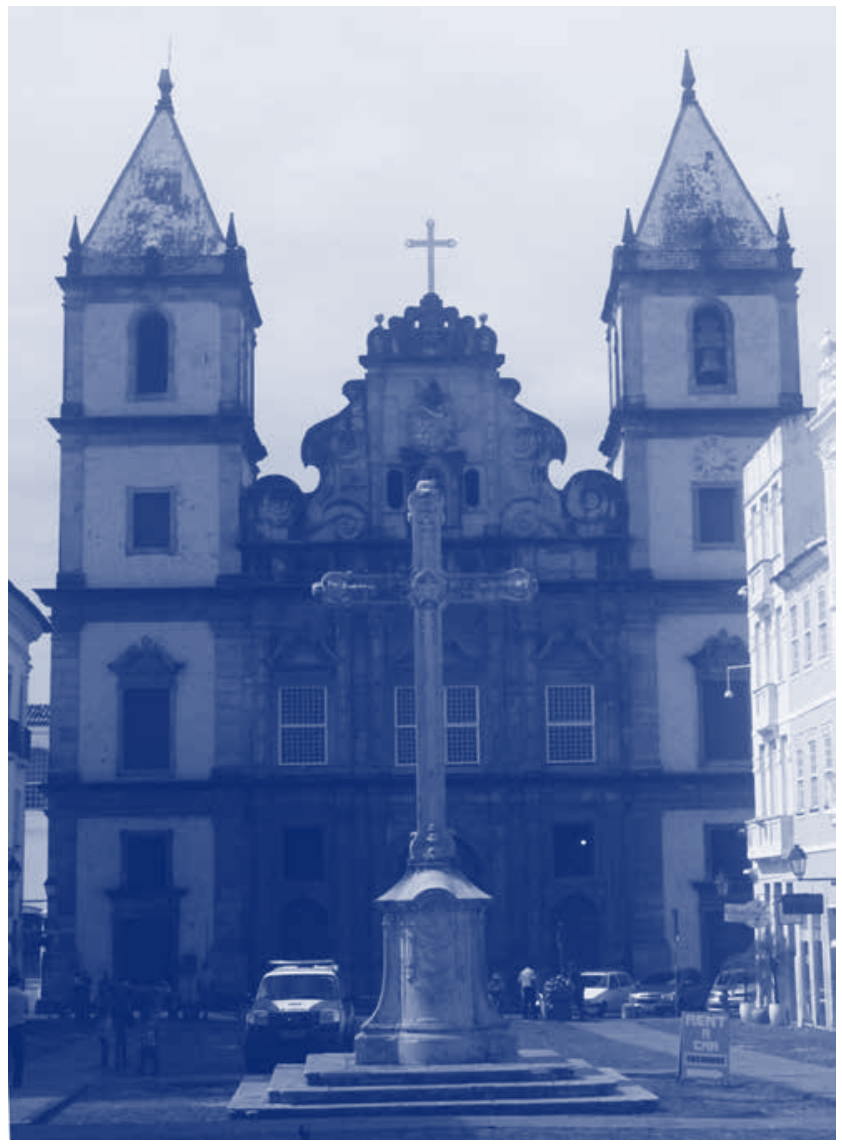

Figura 1: Fachada da Igreja da Ordem Terceira de São Francisco. Fotografia by Lucas Figueiredo Baisch.

Cultural da Humanidade, pela Unesco em 1985 - é um dos mais importantes exemplares do urbanismo ultramarino português. Para um primeiro experimento das potencialidades do processo, a igreja de Sáo Francisco (Figura 1), tombada em 31/03/1938, é escolhida, tornando-a o protótipo para aplicaçóes nas demais edificaçóes eleitas para o projeto.

A edificação está localizada diante da Catedral de Salvador e parcialmente encoberta pelo casario da praça, erguida entre os século XVII e XVIII é considerada uma das mais singulares e ricas expressóes do barroco brasileiro. No seu interior está preservada uma série de azulejos portugueses que retratam Lisboa antes do terremoto de 1755 . No anexo da Igreja, há um pequeno museu com exposição de peças sacras. A pedra fundamental da Igreja de Sáo Francisco foi assentada em 1702, segundo projeto do mestre carpinteiro Gabriel Ribeiro, e inaugurada em julho do ano seguinte (Lins, 2012 p. 225). A igreja possui quatro pavimentos, uma nave única e capela-mor, que se interligam à sacristia, localizada transversalmente ao fundo da construção.

A escolha dessa edificação para iniciar o projeto, dá-se pela potencialidade da forma, pois são identificados paralelapípedos, pirâmides, prismas, planos inclinados e irregulares. $\mathrm{O}$ conjunto desses elementos são manipulados e gerados através de diferentes softwares para o objetivo final da pesquisa, a planificação da edificação. 


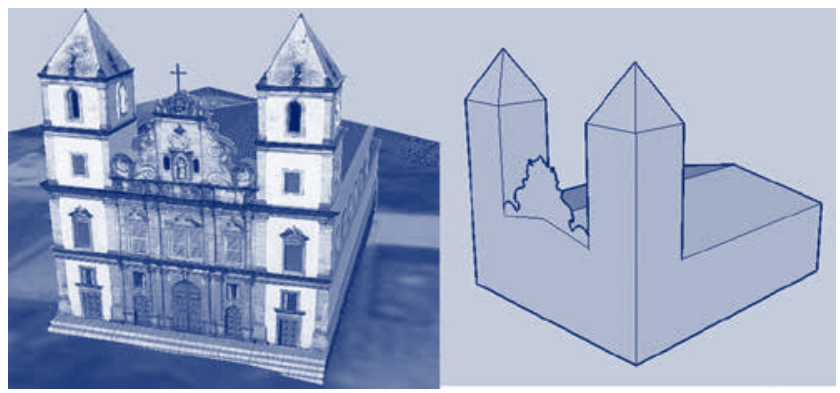

Figura 2: Simplificação do modelo de referência.

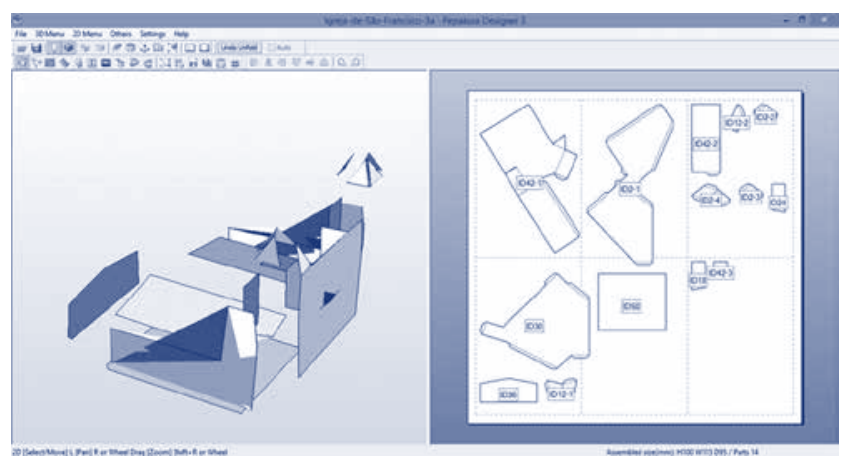

Figura 3: Planificação no Pepakura.
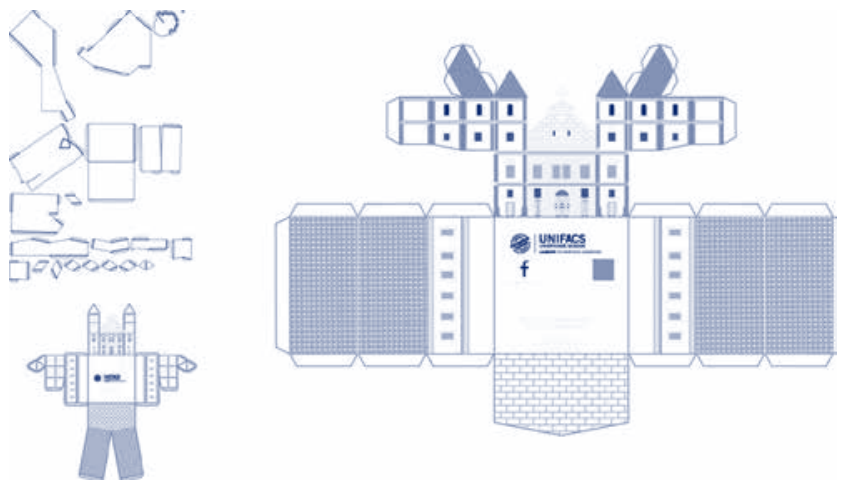

Figura 4: Finalizaçao do modelo planificado no AutoCAD.

\section{Softwares}

Para a confecção do objeto de aprendizagem, utiliza-se os softwares SketchUp ${ }^{\oplus}$ para a modelagem tridimensional, o Pepakura Designer ${ }^{\circ}$, para a planificação e o AutoCAD ${ }^{\oplus}$ para a finalização.

SketchUp ${ }^{\circledast}$ é um software proprietário para a criaçáo de modelos geométricos digitais. Utiliza-se, como referência de medidas e de geometria, o modelo desenvolvido pelo designer Edson Machado no Laboratório de Computação Gráfica Aplicada da Universidade Federal da Bahia (LCAD-UFBA), disponível para download no SketchUp 3D Warehouse.

Para criação da maquete, realiza-se um processo de simplificação do modelo, transformando os volumes em planos, tais como a volumetria de cunhais, cornijas, ornamentos, quadros das janelas, frontáo e da cruz, ainda exclusão do volume posterior e das escadas.
Assim podemos comparar informaçóes do modelo de referência com o modelo simplificado, cujo o tamanho do arquivo diminui de 1,9 MB para 1,3 MB e o número de polígonos é expressivamente reduzido de 2.026 para 19 unidades.

Após essa simplificação, o modelo é preparado em duas dimensôes com o auxílio do Pepakura Designer ${ }^{\circ}$. O software consiste num método desenvolvido para transformar objetos modelados no computador para serem montados em papel.

O Pepakura ${ }^{\oplus}$ racionaliza o modelo tridimensional, une as superfícies adjacentes, planifica e o subdivide, desdobrando em partes correspondentes ao modelo original. O programa também especifica as linhas de corte, vinco e as abas de colagem em cada uma das peças para que sejam posteriormente montadas (Pinheiro, \& Celani, 2008, p. 68). Para esta pesquisa, o resultado da planificaçáo (Figura 3) apresentou um número excessivo de peças segregadas.

A partir desse resultado, exporta-se o arquivo gerado pelo Pepakura ${ }^{\oplus}$ para o AutoCAD ${ }^{\circledR}$ para o agrupamento das peças, aplicaçáo de texturas, cores, representação das fenestraçóes, detalhes da fachada e o estudo de dobras e abas para a montagem final, conforme Figura 4.

A interrelação entre os softwares, a partir da exportação de extensōes, (Tabela 1) é indispensável para o sucesso do workflow entre eles.

Tabela 1: Extensões dos softwares para exportação e importação de arquivos.

\begin{tabular}{|l|l|l|l|}
\hline SHETCH UP & \multicolumn{2}{l|}{ PEPAKURA } & \multicolumn{1}{l|}{ AUTOCAD } \\
\hline $\begin{array}{l}\text { EXPORTA-ÇÃO } \\
\text { File- export - 3d } \\
\text { model }\end{array}$ & $\begin{array}{l}\text { IMPORTAÇÃO } \\
\text { File - Open }\end{array}$ & $\begin{array}{l}\text { EXPORTA- } \\
\text { ÇÃO } \\
\text { File - Export }\end{array}$ & $\begin{array}{l}\text { IMPORTAÇÃO } \\
\text { File - Open }\end{array}$ \\
\hline Collada File (.dae) & Collada File (.dae) & - & - \\
\hline $\begin{array}{l}\text { Google Earth File } \\
\text { (.kmz) }\end{array}$ & $\begin{array}{l}\text { Google Earth File } \\
\text { (.kmz) }\end{array}$ & - & - \\
\hline 3D File (.3ds) & 3D File (.3ds) & - & - \\
\hline $\begin{array}{l}\text { AutoCAD DXF } \\
\text { File (.dxf) }\end{array}$ & AutoCAD (.dxf) & $\begin{array}{l}\text { Drawing } \\
\text { Interchange } \\
\text { Format (.dxf) }\end{array}$ & DXF (.dxf) \\
\hline $\begin{array}{l}\text { AutoCAD File } \\
\text { (.dwg) }\end{array}$ & - & - & Drawing (.dwg) \\
\hline
\end{tabular}

Nota-se que apenas uma extensão, a .dxf, é compatível em todas as etapas do processo.

\section{Impressão e montagem}

Por fim, no teste de impressão são utilizados os papéis sulfite nas gramaturas $90 \mathrm{~g} / \mathrm{m} 2$ e $120 \mathrm{~g} / \mathrm{m} 2$ e couchet nas gramaturas $120 \mathrm{~g} /$ $\mathrm{m} 2,230 \mathrm{~g} / \mathrm{m} 2$ e $300 \mathrm{~g} / \mathrm{m} 2$, a partir da oferta das gráficas da cidade de Salvador, todos em tamanho A3.

Como resultado, o papel sulfite demonstrou maleabilidade no corte, entretanto, as gramaturas não são suficientes para a autosustentação e apresentam enrrugamento na colagem. Assim, opta-se pelo papel couchet de gramatura $300 \mathrm{~g} / \mathrm{m} 2$ pois apresenta estabilidade do modelo e não enrruga na colagem com cola liquida, como visto na Figura 5.

Portanto, a produção de maquetes de edificaçóes históricas, conforme demonstrada nesta pesquisa, mostra que é possível realizar 


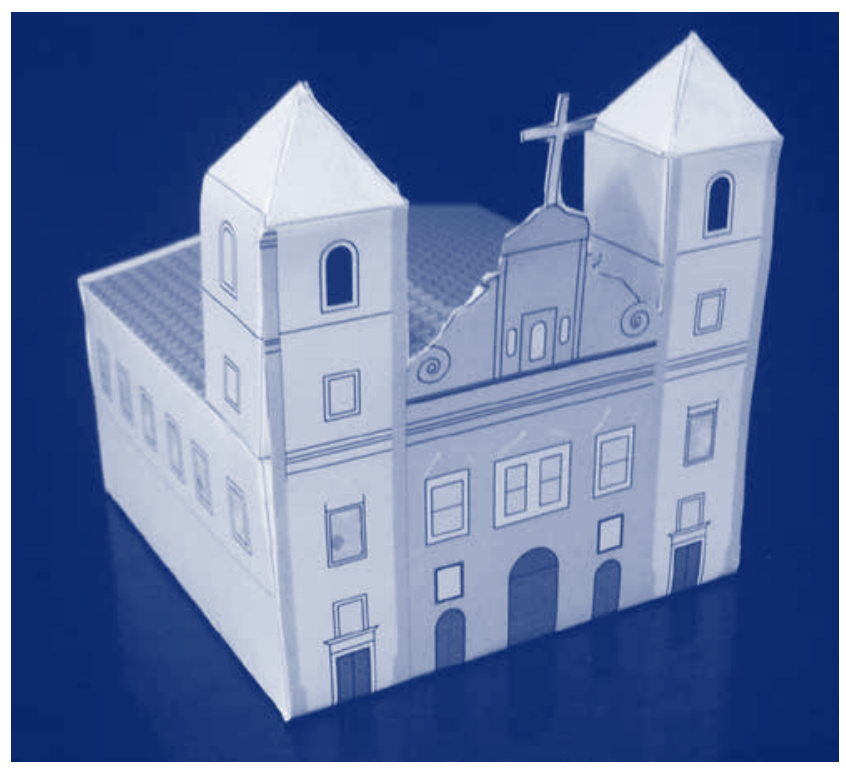

Figura 5: Maquete montada.

um processo integrado entre tecnoloiga e objetos de aprendizagem para uma ação de educaçáo patrimonial.

\section{Resultados e desdobramentos}

O objeto de aprendizagem proposto é um facilitador da educação patrimonial e faz parte da confecção de uma coleção de fascículos com informaçóes sobre diferentes períodos da evoluçáo de Salvador, ainda traz um encarte a planificação do modelo para montagem de coleção de maquete físicas, com o período da edição que dão subsídios aos professores da rede de ensino do município de Salvador e a agentes culturais, que atuam como disseminadores do projeto e serão distribuídos nas escolas atendendo alunos do ensino fundamental.

Como possível desdobramento desta pesquisa, tem-se a ideia de utilizar a Realidade Aumentada. Tal tecnologia é definida como a combinação do ambiente real (maquete) com o ambiente virtual. As interfaces de Realidade Aumentada somam a percepção do usuário sobre o mundo real sobrepondo informaçóes virtuais nele.

No próximo passo, pensa-se a Realidade Aumentada para a visualização de informaçôes sobre a evolução da edificação, através de uma coleção de fotografias antigas encontradas na pesquisa histórica da edificação, além de textos sobre a mesma. Tais informaçóes podem ser acessadas através de um código chamado QRCode abaixo da maquete para que seja visualizado através de aplicativos de leitura no smartphones.

\section{Referências}

BASSO, Ana Carolina Formigoni. A ideia do Modelo Tridimensional em Arquitetura. Dissertação (Mestrado) - Departamento de Arquitetura e Urbanismo, Escola de Engenharia de São Carlos, Universidade de São Paulo, São Carlos, 2005.

COSTA, Heloisa H. G. Cidade capital/ cidade patrimônio: história, memória e inovaçáo na cidade de Salvador-Bahia /1549-2014 - Primeira Etapa : 1549 a 1763. Projeto de Pesquisa. Universidade Federal da Bahia, Salvador, 2014.

HORTA, Maria de L. P. \& GRUNBERG,Evelina \& MONTEIRO, Adriane Q. Guia básico de Educação Patrimonial. Brasília: Iphan; Museu Imperial, 1999.

MILLS, Criss B. PROJETANDO COM MAQUETES. Tradução de Alexandre Salvaterra. 2a . Edição. Porto Alegre: Bookman. 2007.

LINS, Eugênio de Ávila (Coord.). Salvador e a Baía de Todos os Santos. Guia de Arquitetura e Paisagem. Escandón Impressiones, 2012.

PEPAKURA DESIGNER. Disponível em <http://www.tamasoft. co.jp/pepakura-en/>. Acesso em 13 abr 2014.

PINHEIRO, Erica \& CELANI, Gabriela. Produção Digital de Maquetes Arquitetônicas: Um estudo exploratório. Cadernos de Pós-graduação em Arquitetura e Urbanismo. Programa de Pós Graduação em Arquitetura e Urbanismo - FAU-MACKENZIE. São Paulo, 2008.

RISÉRIO, Antônio. Uma história da cidade da Bahia. 2. Ed. Rio de janeiro. Ed. Versal. 2004.

ROCHA, Paulo Mendes da. Maquetes de papel. São Paulo: CosacNaify, 2007.

SKETCH UP. Disponível em <http://www.sketchup.com/pt-BR>. Acesso em 13 abr 2014. Disponível em <https://3dwarehouse. sketchup.com/model.html?id=daffc4b4515622a96f48903e934ecdc3>. Acesso em 21 ago. 2014.

VYGOTSKY, Lev Semenovich. A Formação Social da Mente . São Paulo : Martins Fontes, 1989.

WAJSKOP, Gizela. Brincar na Pré-escola. 2 ed. São Paulo: Cortez Editora, 1997. 